\title{
Grazoprevir and Elbasvir in Patients with Genotype 1 Hepatitis C Virus Infection: A Comprehensive Efficacy and Safety Analysis
}

\author{
Yinan Yao, ${ }^{1}$ Ming Yue, ${ }^{2}$ Jie Wang, ${ }^{3}$ Hongbo Chen, ${ }^{4}$ Mei Liu, ${ }^{1}$ Feng Zang, ${ }^{1}$ Jun Li, \\ Yun Zhang, ${ }^{5}$ Peng Huang, ${ }^{1}$ and Rongbin $\mathbf{Y u}^{1}$ \\ ${ }^{1}$ Department of Epidemiology and Biostatistics, School of Public Health, Nanjing Medical University, Nanjing 211166, China \\ ${ }^{2}$ Department of Infectious Diseases, The First Affiliated Hospital of Nanjing Medical University, Nanjing 210029, China \\ ${ }^{3}$ Department of Basic and Community Nursing, School of Nursing, Nanjing Medical University, Nanjing 211166, China \\ ${ }^{4}$ Department of Infectious Diseases, The Jurong People's Hospital, Jurong 212400, China \\ ${ }^{5}$ Department of Epidemiology, Medical Institute of Nanjing Army, Nanjing 210002, China
}

Correspondence should be addressed to Peng Huang; huangpeng@njmu.edu.cn and Rongbin Yu; rongbinyu@njmu.edu.cn

Received 14 September 2016; Accepted 20 December 2016; Published 9 January 2017

Academic Editor: Mang Ma

Copyright (C) 2017 Yinan Yao et al. This is an open access article distributed under the Creative Commons Attribution License, which permits unrestricted use, distribution, and reproduction in any medium, provided the original work is properly cited.

\begin{abstract}
Background. It is urgent for patients with hepatitis C virus (HCV) infection to find a safe, effective, and interferon-free regimen to optimize therapy. A comprehensive analysis was performed to evaluate the efficacy and safety of the grazoprevir combined with elbasvir, with or without ribavirin (RBV), in 777 treatment-naive and treatment-experienced patients with HCV genotype 1 infection from 3 randomized controlled trials (RCTs). Method. We collected data from the following trials: C-WORTHY (NCT01717326), C-SALVAGE (NCT02105454), and C-EDGE (NCT02105467). All patients received grazoprevir plus elbasvir with or without RBV for 12 or 18 weeks. The sustained virological response (SVR) 12 weeks after end of treatment was calculated for overall and subgroups. Results. 568 (73\%) patients were treatment-naive. Overall, 95\% (95\% CI: 93-96) patients achieved SVR12, 95\% (95\% CI: 92-96) for treatment-naive and 96\% (95\% CI: 92-98) for previously treated patients, respectively. Treatment duration and treatment regimen did not have great difference in SVR12 rates. The most common AEs were fatigue (18\%-29\%), headache (20\%), nausea $(8 \%-14 \%)$, and asthenia $(4 \%-12 \%)$. One patient $(<1 \%)$ receiving grazoprevir plus elbasvir alone and one $(<1 \%)$ receiving grazoprevir plus elbasvir plus RBV had treatment-related serious AEs. Conclusions. The result shows that 12-week grazoprevir plus elbasvir therapy is safe and effective for treatment-naive patients with HCV genotype 1.
\end{abstract}

\section{Introduction}

Hepatitis $\mathrm{C}$ virus (HCV) infection is one of the major global health problems affecting all countries. According to recent estimates, 80-185 million people are infected with HCV worldwide [1, 2]. Chronic HCV infection gives rise to cirrhosis, hepatocellular carcinoma, hepatic decompensation, and liver transplantation [3]. Effective therapy reduces complications and mortality related to HCV infection [4]. These facts illustrate the growing medical need of effective regimens for patients with chronic HCV infection.

The first-line therapies approved for chronic HCV genotype 1 infection patients are sofosbuvir plus peginterferon plus ribavirin and simeprevir plus peginterferon plus ribavirin. The SVR rates were $92 \%$ in treatment-naive patients without cirrhosis (Metavir fibrosis stage F0-F2) and $80 \%$ in those with cirrhosis (Metavir fibrosis stage F4) treated with sofosbuvir plus peginterferon plus ribavirin [5]. In patients treated with simeprevir, peginterferon, and ribavirin, SVR rate in treatment-naive patients infected with $\mathrm{HCV}$ genotype 1 was $83-85 \%$ without cirrhosis but $58-65 \%$ with cirrhosis and $53 \%$ in treatment-experienced patients who had null responses to previous treatment [6-8]. The only available oral regimen for patients with HCV genotype 1 is 24 weeks of sofosbuvir plus ribavirin $[9,10]$. The SVR rate for this regimen was only $68 \%$ overall in treatment-naive patients infected with HCV genotype 1 and without cirrhosis. However, SVR reduced to $50 \%$ in patients with advanced fibrosis [9]. In conclusion, regimens with peginterferon plus first-line protease inhibitors plus ribavirin are less effective and worse tolerated 
TABLE 1: Baseline demographic characteristics.

\begin{tabular}{|c|c|c|c|}
\hline Characteristic & $\begin{array}{l}\text { Treatment-naive } \\
\quad(n=568)\end{array}$ & $\begin{array}{l}\text { Previously treated } \\
\quad(n=209)\end{array}$ & $\begin{array}{c}\text { Total } \\
(n=777)\end{array}$ \\
\hline Mean age, years & 56.5 & 54.3 & 55.9 \\
\hline Mean BMI, kg/m² & 26.44 & 26.98 & 26.59 \\
\hline \multicolumn{4}{|l|}{ Sex } \\
\hline Male, $n(\%)$ & $308(54.2)$ & $120(57.4)$ & $428(55.1)$ \\
\hline Female, $n(\%)$ & $260(45.8)$ & $89(42.6)$ & $349(44.9)$ \\
\hline \multicolumn{4}{|l|}{ Race } \\
\hline White, $n(\%)$ & $420(73.9)$ & $198(94.7)$ & $618(79.5)$ \\
\hline Nonwhite $(n \%)$ & $148(26.1)$ & $11(5.3)$ & $159(20.5)$ \\
\hline \multicolumn{4}{|l|}{ Fibrosis stage } \\
\hline Metavir F0-F2 & $330(58.1)$ & $100(47.8)$ & $430(55.3)$ \\
\hline Metavir F3 & $46(8.1)$ & $27(12.9)$ & $73(9.4)$ \\
\hline Metavir F4 & $192(33.8)$ & $82(39.2)$ & $274(35.3)$ \\
\hline \multicolumn{4}{|l|}{ HCV genotype, $n(\%)$} \\
\hline la & $326(57.4)$ & $106(50.7)$ & $432(55.6)$ \\
\hline $1 b$ & $209(36.8)$ & $103(49.3)$ & $312(40.2)$ \\
\hline 1-other & $33(5.8)$ & 0 & $33(4.2)$ \\
\hline Mean HCV RNA, $\log _{10}(\mathrm{IU} / \mathrm{mL})$ & 6.39 & 6.49 & 6.42 \\
\hline \multicolumn{4}{|l|}{ IL28B CC genotype, $n(\%)$} \\
\hline CC & $172(97.7)$ & $4(2.3)$ & $176(22.7)$ \\
\hline Non-CC & $393(66.5)$ & $198(33.5)$ & $591(76.1)$ \\
\hline Unknown & $3(30.0)$ & $7(70.0)$ & $10(1.3)$ \\
\hline \multicolumn{4}{|l|}{ Regimen received } \\
\hline GZR-EBR 12 weeks & $389(68.5)$ & $33(15.8)$ & $422(54.3)$ \\
\hline GZR-EBR + RBV 12 weeks & $116(20.4)$ & $111(53.1)$ & $227(29.2)$ \\
\hline GZR-EBR 18 weeks & $31(5.5)$ & $32(15.3)$ & $63(8.1)$ \\
\hline GZR-EBR + RBV 18 weeks & $32(5.6)$ & $33(15.8)$ & $65(8.4)$ \\
\hline
\end{tabular}

in patients with cirrhosis [11]. Therefore, an interferon-free, all-oral, short-duration, and effective HCV therapy is highly needed for all kinds of patients.

We performed this post hoc analysis in order to better determine the safety and efficacy of grazoprevir (an HCV NS3/4A protease inhibitor) plus elbasvir (an HCV NS5A inhibitor) in patients with HCV genotype 1 infection as well as provide the evidence for choosing the optimal treatment regimen.

\section{Methods}

We collected data from the following trials: C-WORTHY (NCT01717326) [12, 13], C-SALVAGE (NCT02105454), [14] and C-EDGE (NCT02105467) [15]. We included patients infected with $\mathrm{HCV}$ with or without cirrhosis that received a fixed dose of 12 weeks or 18 weeks of GZR (100 mg) and EBR (50 mg), orally once-daily, with or without ribavirin for efficacy and safety analysis. Daily doses of ribavirin were based on the body weight of patients $(51-65 \mathrm{~kg}, 800 \mathrm{mg} /$ day; 66-80 kg, $1000 \mathrm{mg} /$ day; 81-105 kg, $1200 \mathrm{mg} /$ day; and >105 kg to $125 \mathrm{~kg}, 1400 \mathrm{mg} /$ day), orally twice-daily in the morning and in the evening. Sustained virological response at 12 weeks (SVR12) after treatment and its two-sided 95\% confidence intervals (CIs) were estimated. Comparisons between contingency tables were made by Fisher's exact test or chi-square test, with two-sided $P$ value $<0.05$ as significant.

\section{Results}

3.1. Baseline Characteristics. Data was pooled from three clinical trials conducted in the United States, Austria, Israel, Spain, Australia, Czech Republic, France, Germany, South Korea, Sweden, and Taiwan. There were four articles. Three were phase II and one was phase III. Table 1 shows demographic characteristics of the patients included in this analysis. A total of 777 patients were enrolled in this analysis. Most of the patients were treatment-naive (73\%), male (55\%), white $(80 \%)$, and with a median age of 56 years. Of these patients, 273 (35\%) patients had cirrhosis. 432 (56\%) patients had genotype la infection and 591 (76\%) patients were IL28B non-CC.

These patients were divided into four groups by treatment regimen as follows: 422 (54\%) received 12 weeks of 
TABLE 2: SVR12 by baseline factors, treatment history, and regimen.

\begin{tabular}{lccc}
\hline Response & $\begin{array}{c}\text { Total } \\
(n / N, \%)\end{array}$ & $\begin{array}{c}\text { Treatment-naive } \\
(n / N, \%)\end{array}$ & $\begin{array}{c}\text { Previously treated } \\
(n / N, \%)\end{array}$ \\
\hline Overall (\%) & $737 / 777(95)$ & $537 / 568(95)$ & $200 / 209(96)$ \\
95\% CI & $(93,96)$ & $(92,96)$ & $(92,98)$ \\
By treatment duration (\%) & & & 0.519 \\
12 weeks & $613 / 649(94)$ & $477 / 505(94)$ & $136 / 144(94)$ \\
18 weeks & $124 / 128(97)$ & $60 / 63(95)$ & $64 / 65(98)$ \\
By regimen (\%) & & $399 / 420(95)$ & 0.996 \\
Without RBV & $460 / 485(95)$ & $138 / 148(93)$ & 0.361 \\
With RBV & $277 / 292(95)$ & & $139 / 144(97)$ \\
By treatment duration + regimen (\%) & & $370 / 389(95)$ & 0.204 \\
GZR-EBR 12 weeks & $400 / 422(95)$ & $107 / 116(92)$ & $30 / 33(91)$ \\
GZR-EBR + RBV 12 weeks & $213 / 227(94)$ & $29 / 31(94)$ & $106 / 111(96)$ \\
GZR-EBR 18 weeks & $60 / 63(95)$ & $31 / 32(97)$ & $31 / 32(97)$ \\
GZR-EBR + RBV 18 weeks & $64 / 65(99)$ & $33 / 33(100)$ \\
\hline
\end{tabular}

${ }^{*}$ They were compared between treatment-naïve and previously treated groups.

grazoprevir plus elbasvir, 227 (29\%) received grazoprevir plus elbasvir plus RBV, 63 (8\%) received 18 weeks of grazoprevir plus elbasvir, and $65(8 \%)$ received 18 weeks of grazoprevir plus elbasvir plus RBV.

3.2. Efficacy. 95\% (95\% CI: 93-96, Table 2) of 777 patients achieved SVR12. The SVR12 rates for treatment-naive patients were 95\% (95\% CI: 92-96) and 96\% (95\% CI: 92-98) for previously treated patients. The SVR12 rates were $94 \%(95 \%$ CI: 92-96) for patients receiving 12 weeks of treatment and 97\% (95\% CI: 92-99) for those receiving 18 weeks of treatment. The rates were generally similar in subgroups, even with the cofactors of treatment duration and the regimen with or without RBV (Table 2), but SVR12 of the 33 treatmentexperienced patients receiving 12 weeks of grazoprevir plus elbasvir without RBV was $91 \%$ (95\% CI: 76-98). This was relatively lower than the $96 \%-100 \%$ SVR12 rates when the regimen added $\mathrm{RBV}$ or when the duration was extended to 18 weeks.

We merged three of the four included articles with related information for subgroup analysis (Table 3) [13-15]. And in the subgroup of age, only two articles were included $[14,15]$. This analysis did not identify significant differences for comparisons of treatment-naive and previously treated patients for many factors including sex, age, race, HCV subtype, IL28B genotype, baseline HCV RNA, baseline NS3/4A, or NS5A RAS $(P>0.05)$. Two patients missing the data for IL28B genotype were excluded from this subgroup. NS3/4A RAS were identified at baseline in patients with genotype la or 1b infection; SVR12 was achieved in 138 of 145 and 206 of 213 patients with or without baseline RAS, respectively. Response was generally similar with or without NS3/4A RAS. NS5A RAS were also detected at baseline in genotype 1a or $1 \mathrm{~b}$ infected patients. However, the rate of SVR12 was $99 \%$ (315/31, 95\% CI: 97-100) in patients without baseline NS5A RAS, compared with $76 \%(34 / 45,95 \%$ CI: $60-87)$ in patients with baseline NS5A RAS, without overlapping 95\% CIs $(P<$ 0.001) (Table 3).

3.3. Safety. Grazoprevir plus elbasvir was generally welltolerated. Patients receiving 12 weeks and 18 weeks of grazoprevir plus elbasvir with RBV had more adverse events (AEs) than those receiving 12 weeks and 18 weeks of grazoprevir plus elbasvir alone. The most common AEs were fatigue, headache, nausea, and asthenia (Table 4). These events were more common in patients receiving RBV (29\%, 20\%, 14\%, and $12 \%$ ) than in those receiving grazoprevir plus elbasvir alone $(18 \%, 20 \%, 8 \%$, and $4 \%$, resp.). And patients treated for 18 weeks had relatively higher rates of fatigue, headache, asthenia, nausea, and diarrhoea than those treated only for 12 weeks. In patients receiving grazoprevir plus elbasvir alone, the adverse events of headache and asthenia in patients treated for 18 weeks were significantly higher than those treated for 12 weeks $(P=0.015, P<0.001$, resp.). Besides, the rate of suffering at least one adverse event was significantly higher in 18-week treatment than 12-week when including $\operatorname{RBV}(P=0.018)$.

Patients receiving grazoprevir plus elbasvir with or without RBV both had serious adverse events (SAEs) of $3 \%$ $(13 / 484,8 / 293$, resp.). Two (<1\%) SAEs were considered treatment-related according to the investigator (one case of abdominal pain, the other case of nausea). Overall, $3(<1 \%)$ patients discontinued grazoprevir plus elbasvir and 4 (1\%) discontinued grazoprevir plus elbasvir plus RBV because of an AE. Two patients receiving 12 weeks of grazoprevir plus elbasvir alone discontinued due to elevated liver aminotransferase levels and 1 discontinued because of palpitations and anxiety on treatment day 4 . Three patients receiving 12 weeks of grazoprevir plus elbasvir plus RBV discontinued due to atrial fibrillation, drug intolerance, and death. One patient receiving 18 weeks of grazoprevir plus elbasvir plus RBV discontinued due to uterine bleeding. 
TABLE 3: Subgroup analysis of SVR12.

\begin{tabular}{|c|c|c|c|c|c|}
\hline Variables & Total, $n / N$ & SVR12 (95\% CI), \% & $\begin{array}{c}\text { Treatment-naive } \\
(n / N, \%)\end{array}$ & $\begin{array}{c}\text { Previously treated } \\
(n / N, \%)\end{array}$ & $P^{\mathrm{d}}$ \\
\hline \multicolumn{6}{|l|}{ Sex $^{*}$} \\
\hline Male & $260 / 280$ & $93(89-96)$ & $217 / 234(93)$ & $43 / 46(93)$ & 1.000 \\
\hline Female & $237 / 244$ & 97 (94-99) & $204 / 211(97)$ & $33 / 33(100)$ & 0.598 \\
\hline \multicolumn{6}{|l|}{$\operatorname{Age}^{\mathrm{a}}$} \\
\hline$\geq 65$ years & $39 / 40$ & $98(87-100)$ & $29 / 29(100)$ & 10/11 (91) & 0.275 \\
\hline$<65$ years & $336 / 355$ & $95(92-97)$ & $270 / 287(95)$ & $66 / 68(97)$ & 0.548 \\
\hline \multicolumn{6}{|l|}{ Race $^{*}$} \\
\hline White & $365 / 385$ & $95(92-97)$ & 291/308 (94) & $74 / 77$ (96) & 0.776 \\
\hline Nonwhite & $132 / 139$ & $95(90-98)$ & 130/137 (95) & $2 / 2(100)$ & 1.000 \\
\hline \multicolumn{6}{|l|}{ Genotype* } \\
\hline la & $250 / 269$ & $93(89-96)$ & $222 / 239(93)$ & $28 / 30(93)$ & 1.000 \\
\hline $1 b$ & $219 / 225$ & $97(94-99)$ & $171 / 176(97)$ & $48 / 49(98)$ & 1.000 \\
\hline 1-other & $28 / 30$ & $93(78-99)$ & $28 / 30(93)$ & 0 & - \\
\hline \multicolumn{6}{|l|}{ IL $28 B$ genotype $\mathrm{b}^{\mathrm{b}}$} \\
\hline $\mathrm{CC}$ & $127 / 136$ & $93(88-97)$ & $125 / 134(93)$ & $2 / 2(100)$ & 1.000 \\
\hline Non-CC & $368 / 385$ & $96(93-97)$ & $294 / 308(95)$ & $74 / 77(96)$ & 1.000 \\
\hline Unknown & $1 / 1$ & $100(25-100)$ & $1 / 1(100)$ & 0 & - \\
\hline \multicolumn{6}{|l|}{ Baseline HCV RNA* } \\
\hline$\leq 800000 \mathrm{IU} / \mathrm{mL}$ & $153 / 156$ & $98(94-100)$ & $126 / 127(99)$ & $27 / 29(93)$ & 0.089 \\
\hline$>800000 \mathrm{IU} / \mathrm{mL}$ & $344 / 368$ & $93(90-96)$ & $295 / 318(93)$ & $49 / 50(98)$ & 0.225 \\
\hline \multicolumn{6}{|c|}{ NS3/4A RAS at baseline ${ }^{c}$} \\
\hline Baseline RAS & $138 / 145$ & $95(90-98)$ & 107/111 (96) & $31 / 34(91)$ & 0.355 \\
\hline No baseline RAS & $206 / 213$ & $97(93-99)$ & $162 / 169(96)$ & $44 / 44(100)$ & 0.349 \\
\hline \multicolumn{6}{|c|}{ NS5A RAS at baseline ${ }^{c}$} \\
\hline Baseline RAS & $34 / 45$ & $76(60-87)$ & $28 / 37(76)$ & $6 / 8(75)$ & 1.000 \\
\hline No baseline RAS & $315 / 318$ & $99(97-100)$ & $245 / 247(99)$ & $70 / 71(99)$ & 0.533 \\
\hline
\end{tabular}

${ }^{*}$ Three articles reporting the variables were included [13-15].

${ }^{\mathrm{a}}$ One of the three articles not reporting the variable was excluded [13].

${ }^{\mathrm{b}}$ Three articles were included. Two patients were missing data for IL28B genotype and were excluded. SVR12 was achieved in 1 of these 2 patients (50.0\%, CI: $1.3 \%$ to $98.7 \%)$

${ }^{c}$ One of the three articles not reporting the variable was excluded [2], and only genotypes la and $1 \mathrm{~b}$ were reported. One of 79 patients in study 4 was sequenced of NS5A but not sequenced of NS3/4A.

${ }^{\mathrm{d}}$ They were compared between treatment-naïve and previously treated groups.

\section{Discussion}

Most of the individuals $(96 \%, 744 / 777)$ in this post hoc analysis are infected with HCV genotype 1 . There were no differences between all subgroups for the rate of SVR12. Subgroup analysis showed no significance of sex, age, race, HCV subtype, IL28B genotype, or baseline HCV RNA on treatment outcome. High rates of SVR12 were shown across all groups regardless of adding RBV or extending treatment duration from 12 to 18 weeks. Specifically, the efficacy of 12 weeks of grazoprevir plus elbasvir without ribavirin was $95 \%$ (95\% CI: 92-97) in treatment-naive patients and 91\% (95\% CI: 76-98) in treatment-experienced patients. Nevertheless, due to the difficulty of information extraction, few genotype
4 and 6 infected patients were also included in this analysis. The efficacy of these patients was lack of evidence at present; more patients need to be included in clinical trials to obtain sufficient evidence.

The treatment success in hard-to-cure patients can be used to evaluate the efficacy of a therapy. Treatment-naive patients with cirrhosis and previous null response patients with or without cirrhosis with genotype 1 infection were included in the C-WORTHY study. All patients receiving grazoprevir plus elbasvir with or without RBV achieved high rates of efficacy. The sustained virological response of 12 weeks of grazoprevir plus elbasvir without RBV was $97 \%$ in treatment-naive patients with cirrhosis, $91 \%$ in previous null response patients with or without RBV, and $92 \%$ in 


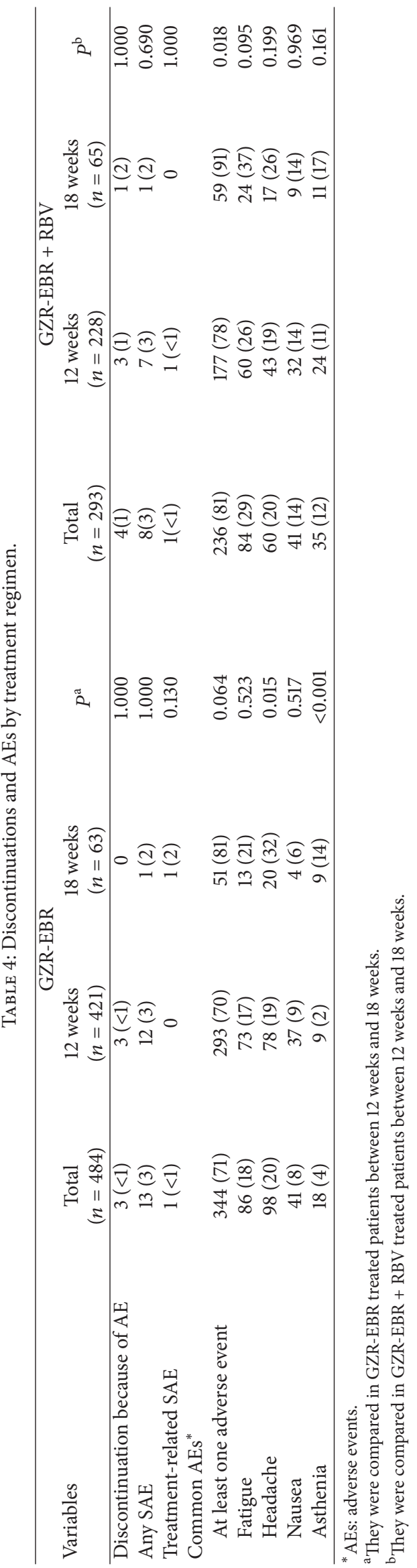


previous null response patients with cirrhosis [12]. For many therapies, sustained virological response can substantially decrease in treatment-experienced (peginterferon plus ribavirin), cirrhotic patients compared to those treatmentnaive, noncirrhotic patients with high rate of SVR [6, 7, 16]. Among other all-oral regimens, there still remain some limitations. In a clinical trial of sofosbuvir plus ledipasvir with or without ribavirin, the overall efficacy in previously treated patients was 94-99\%. However, the efficacy of 12-week ribavirin-free regimen was $86 \%$ in patients with cirrhosis and $87 \%$ in genotype $1 \mathrm{~b}$ patients [17]. In patients receiving ABT-450 plus ritonavir plus ombitasvir plus dasabuvir plus ribavirin with cirrhosis, the SVR12 rates of 12 or 24 weeks of treatment were $92 \%$ or $96 \%$, respectively, while adverse events increased [16]. In addition, a regimen of 12 weeks of simeprevir plus sofosbuvir with or without ribavirin in well compensated patients with cirrhosis showed the SVR12 rate of 89\% [18]. The C-WORTHY study showed the high efficacy of NS3/4A protease inhibitor (grazoprevir) plus NS5A inhibitor (elbasvir), including the patients with poor response to other therapies [12]. However, most of the patients in this analysis were well compensated; the efficacy and safety of grazoprevir plus elbasvir in those with decompensated disease were not involved. A further study is urgent for such patients to evaluate the efficacy and safety of this regimen.

The prevalence of $\mathrm{HCV}$ infection is about one-third among HIV-infected patients [19]. 59 previously untreated coinfected individuals with $\mathrm{HCV}$ genotype 1 were also enrolled in the C-WORTHY trial. The response in monoinfected patients receiving 12 weeks of treatment was $93 \%$ with ribavirin and $98 \%$ without ribavirin, yet, in coinfected patients, the efficacy was $97 \%$ (28/29, 95\% CI: 82-100) with ribavirin and $87 \%$ (87\%, 95\% CI: 69-96) without ribavirin [13]. There is no difference between monoinfected and coinfected patients or regimens with or without ribavirin based on the $95 \%$ CIs. Historical cross-study comparisons have demonstrated that $\mathrm{HIV} / \mathrm{HCV}$ coinfection is one of the reasons for poor response to interferon-based $\mathrm{HCV}$ therapy. In large studies of peginterferon alfa-2a (APRICOT [20]) and alfa-2b (RIBAVIC [21]) plus ribavirin, response in coinfected patients with HCV genotype 1 was about half of that in monoinfected patients $(29 \%, 20 \%$, resp.) $[22,23]$. The results of the C-WORTHY study suggest that grazoprevir plus elbasvir may be effective for both monoinfected and coinfected patients. The relatively small number of coinfected patients may be one of the limitations of the trial and the fairly easy-to-cure patients may be another.

According to this analysis, the regimen of grazoprevir plus elbasvir with or without ribavirin was well-tolerated. The frequency of serious adverse events and discontinuity because of adverse events was low ( $3 \%$ and $<1 \%$, resp.). The frequency was similar in patients with or without ribavirin. However, the incidence of adverse events was lower in ribavirin-free groups. Similarly, ribavirin also contributed to the adverse events [24]. Due to the high rates of SVR12 without ribavirin, the ideal regimen could be ribavirin-free.

The NS3/4A resistance-associated variants (RAS) at baseline did not affect the efficacy of grazoprevir plus elbasvir with or without ribavirin significantly. 95\% (95\% CI: 90-98) of the patients with NS3/4A RAS achieved SVR12. The association between baseline NS5A RAS and SVR12 was discovered. 99\% (95\% CI: 97-100) of the patients without baseline NS5A RAS achieved SVR12 while only 76\% (95\% CI: 60-87) of the patients with baseline NS5A RAS achieved SVR12. Therefore, preexisting of NS5A RAS may influence the efficacy obviously. Of course, this result was not representative due to lack of information.

The lack of innovation is a limitation of our study. However, it is still necessary to conduct this comprehensive analysis since grazoprevir plus elbasvir with or without ribavirin is a new all-oral therapy for HCV infection and it has not been approved in China. Second, this study increased the sample size; the results of this analysis were more representative and persuasive. In addition, $\mathrm{HCV}-1$ genotype is the most common one and we only carried out this comprehensive analysis on it. The confounding factors of other genotypes were controlled effectively.

In summary, this analysis suggests that the oral fixeddose combination of an NS3/4A protease inhibitor (grazoprevir) and NS5A inhibitor (elbasvir) is effective and welltolerated for treatment-naive and previously treated patients with chronic genotype $1 \mathrm{HCV}$ infection. Adding RBV or extending treatment duration may be of little benefit, except for treatment-experienced patients. The regimen of all-oral, 2-drug combination with or without RBV provides a new therapeutic option for chronic HCV infection.

\section{Conclusion}

12-week grazoprevir plus elbasvir therapy is safe and effective for treatment-naive patients with HCV genotype 1.

\section{Competing Interests}

The authors declare no conflict of interests.

\section{Authors' Contributions}

Rongbin Yu and Peng Huang participated in the design of the study. Yinan Yao, Ming Yue, Mei Liu, and Feng Zang took charge of data collection and quality control. Yinan Yao, Jie Wang, and Hongbo Chen performed the statistical analysis. Jun Li and Yun Zhang contributed materials and analysis tools. Yinan Yao, Ming Yue, and Peng Huang wrote the paper. All authors read and approved the final manuscript. Yinan Yao and Ming Yue contributed equally to this paper.

\section{Acknowledgments}

The current study was supported in part by National Natural Science Foundation of China (nos. 81473029, 81502853, and 81473028), Natural Science Foundation of Jiangsu Province (BK20151026), Medical Reform Project of Health and Family Planning Commission of Jiangsu Province of China (YG201413), and Priority Academic Program Development (PAPD) of Jiangsu Higher Education Institutions. 


\section{References}

[1] K. Mohd Hanafiah, J. Groeger, A. D. Flaxman, and S. T. Wiersma, "Global epidemiology of hepatitis $\mathrm{C}$ virus infection: new estimates of age-specific antibody to HCV seroprevalence," Hepatology, vol. 57, no. 4, pp. 1333-1342, 2013.

[2] World Health Organization, Guidelines for the Screening, Care and Treatment of Persons with Hepatitis C Infection, World Health Organization, 2014.

[3] B. Hajarizadeh, J. Grebely, and G. J. Dore, "Epidemiology and natural history of HCV infection," Nature Reviews Gastroenterology and Hepatology, vol. 10, no. 9, pp. 553-562, 2013.

[4] B. L. Pearlman and N. Traub, "Sustained virologic response to antiviral therapy for chronic hepatitis $\mathrm{C}$ virus infection: a cure and so much more," Clinical Infectious Diseases, vol. 52, no. 7, pp. 889-900, 2011.

[5] E. Lawitz, A. Mangia, D. Wyles et al., "Sofosbuvir for previously untreated chronic hepatitis C infection," The New England Journal of Medicine, vol. 368, no. 20, pp. 1878-1887, 2013.

[6] M. Manns, P. Marcellin, F. Poordad et al., "Simeprevir with pegylated interferon alfa $2 \mathrm{a}$ or $2 \mathrm{~b}$ plus ribavirin in treatmentnaive patients with chronic hepatitis $C$ virus genotype 1 infection (QUEST-2): a randomised, double-blind, placebocontrolled phase 3 trial," The Lancet, vol. 384, no. 9941, pp. 414426, 2014.

[7] I. M. Jacobson, G. J. Dore, G. R. Foster et al., "Simeprevir with pegylated interferon alfa $2 \mathrm{a}$ plus ribavirin in treatment-naive patients with chronic hepatitis $\mathrm{C}$ virus genotype 1 infection (QUEST-1): a phase 3, randomised, double-blind, placebocontrolled trial," The Lancet, vol. 384, no. 9941, pp. 403-413, 2014.

[8] S. Zeuzem, T. Berg, E. Gane et al., "Simeprevir increases rate of sustained virologic response among treatment-experienced patients with HCV genotype-1 infection: a phase IIb trial," Gastroenterology, vol. 146, no. 2, pp. 430.e6-441.e6, 2014.

[9] A. Osinusi, E. G. Meissner, Y.-J. Lee et al., "Sofosbuvir and ribavirin for hepatitis $\mathrm{C}$ genotype 1 in patients with unfavorable treatment characteristics: a randomized clinical trial," JAMA Journal of the American Medical Association, vol. 310, no. 8, pp. 804-811, 2013.

[10] S. Naggie, M. Sulkowski, J. Lalezari, J. Fessel, and K. Mounzer, "Sofosbuvir plus ribavirin for HCV genotype 1-3 infection in HIV coinfected patients (PHOTON-1)," in Proceedings of the 21st Conference on Retroviruses and Opportunistic Infections, pp. 3-6, Boston, Mass, USA, March 2014.

[11] C. Hézode, H. Fontaine, C. Dorival et al., "Effectiveness of telaprevir or boceprevir in treatment-experienced patients with HCV genotype 1 infection and cirrhosis," Gastroenterology, vol. 147, no. 1, pp. 132-142.e4, 2014.

[12] E. Lawitz, E. Gane, B. Pearlman et al., "Efficacy and safety of 12 weeks versus 18 weeks of treatment with grazoprevir (MK-5172) and elbasvir (MK-8742) with or without ribavirin for hepatitis $\mathrm{C}$ virus genotype 1 infection in previously untreated patients with cirrhosis and patients with previous null response with or without cirrhosis (C-WORTHY): a randomised, open-label phase 2 trial," The Lancet, vol. 385, no. 9973, pp. 1075-1086, 2015.

[13] M. Sulkowski, C. Hezode, J. Gerstoft et al., "Efficacy and safety of 8 weeks versus 12 weeks of treatment with grazoprevir (MK-5172) and elbasvir (MK-8742) with or without ribavirin in patients with hepatitis $\mathrm{C}$ virus genotype 1 mono-infection and HIV/hepatitis C virus co-infection (C-WORTHY): a randomised, open-label phase 2 trial," The Lancet, vol. 385, no. 9973, pp. 1087-1097, 2015.
[14] X. Forns, S. C. Gordon, E. Zuckerman et al., "Grazoprevir and elbasvir plus ribavirin for chronic HCV genotype-1 infection after failure of combination therapy containing a direct-acting antiviral agent," Journal of Hepatology, vol. 63, no. 3, pp. 564572,2015

[15] S. Zeuzem, R. Ghalib, K. R. Reddy et al., "Grazoprevirelbasvir combination therapy for treatment-naive cirrhotic and noncirrhotic patients with chronic hepatitis $\mathrm{C}$ virus genotype 1, 4, or 6 infection: a randomized trial," Annals of Internal Medicine, vol. 163, no. 1, pp. 1-13, 2015.

[16] F. Poordad, C. Hezode, R. Trinh et al., "ABT-450/r-ombitasvir and dasabuvir with ribavirin for hepatitis $\mathrm{C}$ with cirrhosis," The New England Journal of Medicine, vol. 370, no. 21, pp. 1973-1982, 2014.

[17] N. Afdhal, K. R. Reddy, D. R. Nelson et al., "Ledipasvir and sofosbuvir for previously treated HCV genotype 1 infection," New England Journal of Medicine, vol. 370, no. 16, pp. 1483-1493, 2014.

[18] E. Lawitz, M. S. Sulkowski, R. Ghalib et al., "Simeprevir plus sofosbuvir, with or without ribavirin, to treat chronic infection with hepatitis $\mathrm{C}$ virus genotype 1 in non-responders to pegylated interferon and ribavirin and treatment-naive patients: the COSMOS randomised study," The Lancet, vol. 384, no. 9956, pp. 1756-1765, 2014.

[19] K. E. Sherman, S. D. Rouster, R. T. Chung, and N. Rajicic, "Hepatitis C virus prevalence among patients infected with human immunodefidency virus: a cross-sectional analysis of the US Adult AIDS clinical trials group," Clinical Infectious Diseases, vol. 34, no. 6, pp. 831-837, 2002.

[20] F. J. Torriani, M. Rodriguez-Torres, J. K. Rockstroh et al., "Peginterferon alfa-2a plus ribavirin for chronic hepatitis C virus infection in HIV-infected patients," New England Journal of Medicine, vol. 351, no. 5, pp. 438-450, 2004.

[21] F. Carrat, F. Bani-Sadr, S. Pol et al., "Pegylated interferon alfa$2 \mathrm{~b}$ vs standard interferon alfa- $2 \mathrm{~b}$, plus ribavirin, for chronic hepatitis C in HIV-infected patients: a randomized controlled trial," The Journal of the American Medical Association, vol. 292, no. 23, pp. 2839-2848, 2004.

[22] M. Rodriguez-Torres, J. Slim, L. Bhatti et al., "Peginterferon alfa2a plus ribavirin for HIV-HCV genotype 1 coinfected patients: a randomized international trial," HIV Clinical Trials, vol. 13, no. 3, pp. 142-152, 2012.

[23] S. J. Hadziyannis, H. Sette Jr., T. R. Morgan et al., "Peginterferon$\alpha 2 \mathrm{a}$ and ribavirin combination therapy in chronic hepatitis $\mathrm{C}$ : a randomized study of treatment duration and ribavirin dose," Annals of Internal Medicine, vol. 140, no. 5, pp. 346-355, 2004.

[24] N. Afdhal, S. Zeuzem, P. Kwo et al., "Ledipasvir and sofosbuvir for untreated HCV genotype 1 infection," The New England Journal of Medicine, vol. 370, no. 20, pp. 1889-1898, 2014. 


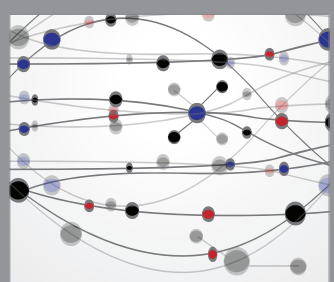

The Scientific World Journal
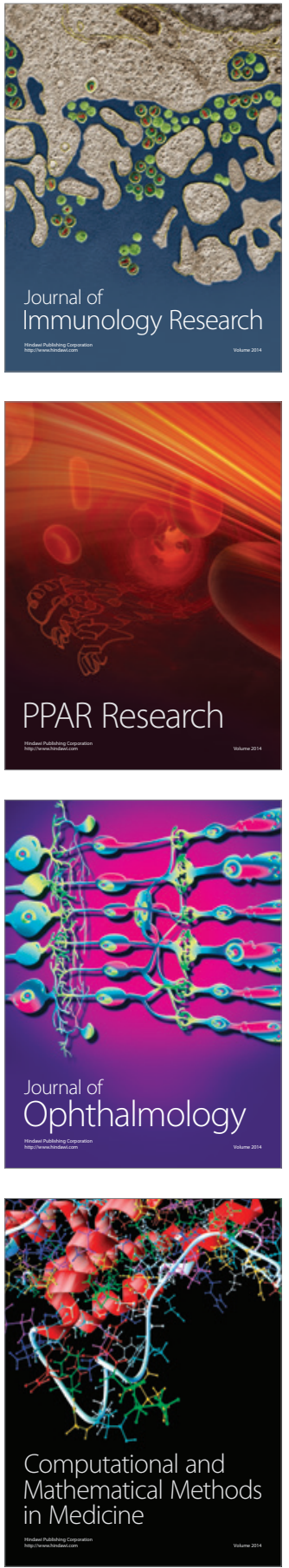

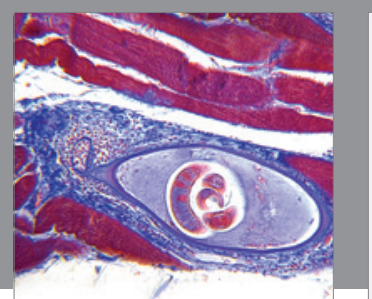

Gastroenterology Research and Practice
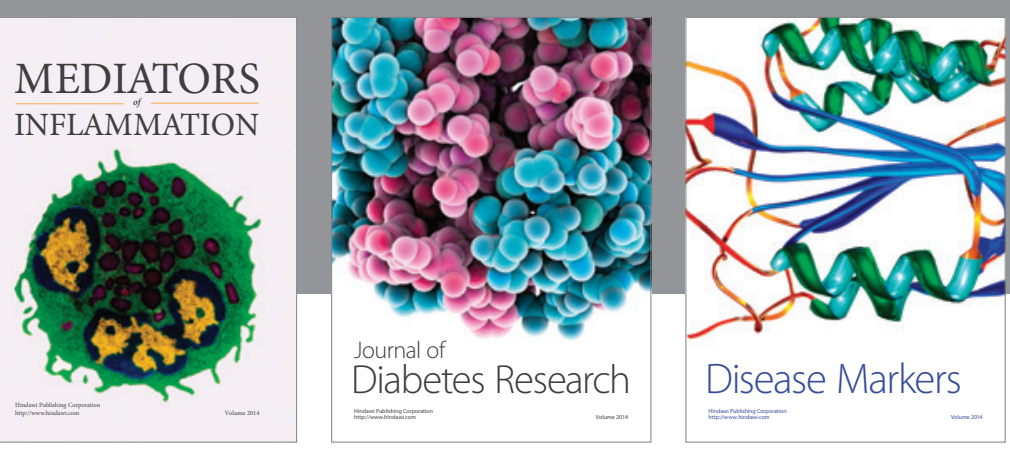

Disease Markers

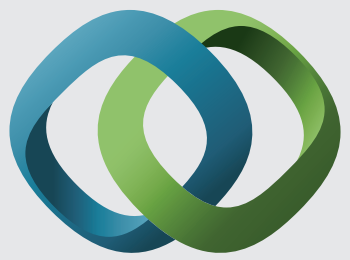

\section{Hindawi}

Submit your manuscripts at

https://www.hindawi.com
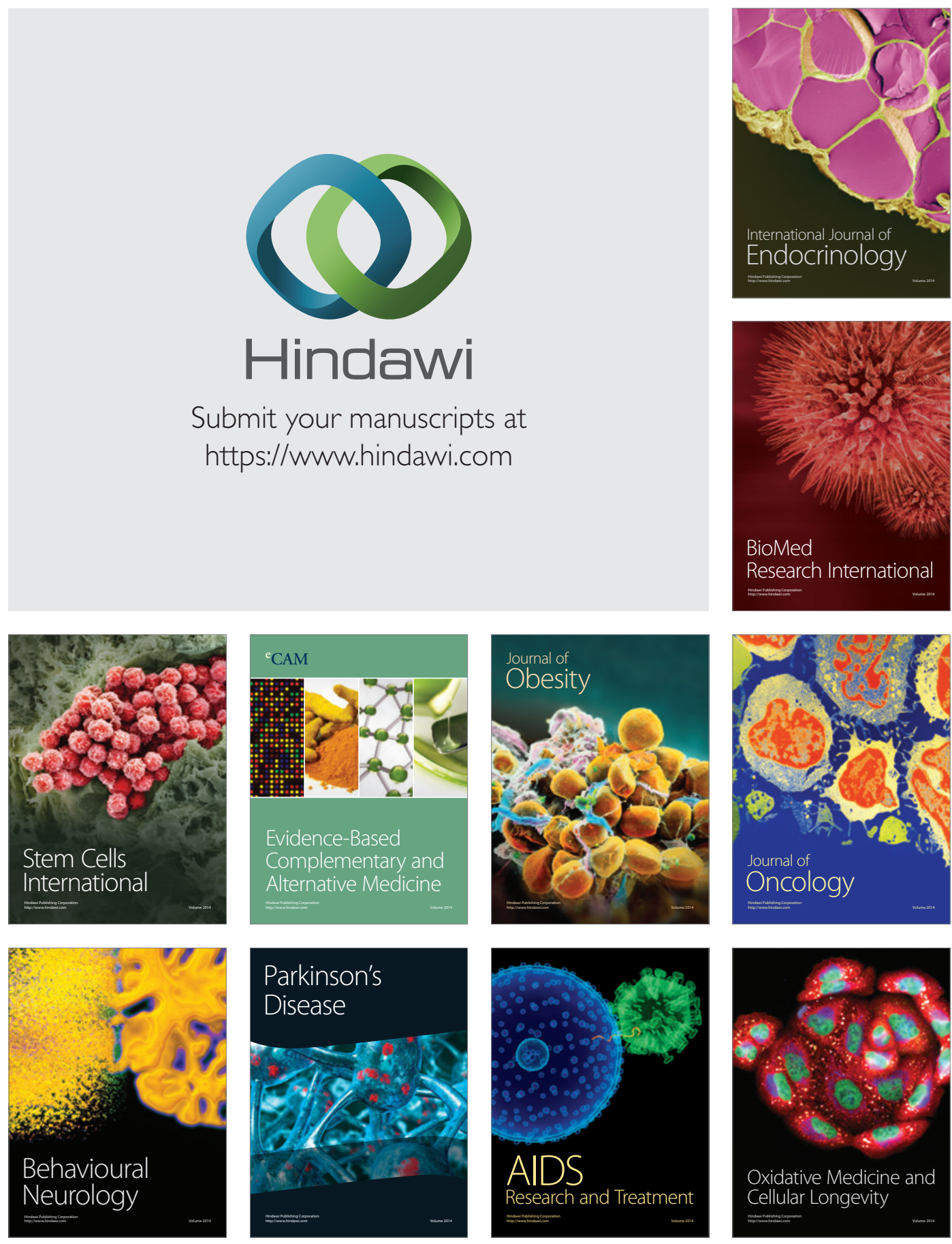